\title{
Morphometric Dimensions of Syrian Golden Hamster Pancreas of Both Sexes
}

\author{
By \\ Rumio TAGA*, Marcelo Ribeiro FAVERÃO**, Tania Mary CESTARI and \\ Gerson Francisco de ASSIS
}

Histology Laboratory, Department of Morphology, Faculty of Odontology of Bauru, USP, Brazil

- Received for Publication, November 26, 1998 -

\begin{abstract}
Key Words: Pancreas, Hamster, Stereology, Acinus, Intercalated duct, Excretory duct, Pancreatic islets
Summary: The morphometric dimensions of the various structures of the pancreas of adult Syrian golden hamsters, of both sexes, were evaluated using stereological methods. The average body mass of the animals used was $133.8 \pm 2.45 \mathrm{~g}$ and $140.6 \pm 7.98 \mathrm{~g}$ for the males and females, respectively, and the pancreatic mass, $389.9 \pm 14.88$ and $409.7 \pm 21.42 \mathrm{mg}$, respectively. The analysis of variance of the obtained data showed that: a) the acini, intercalated ducts and stroma did not present statistically significant differences in any of the dimensions evaluated, with the exception of the nucleus volume of the acinar cells which was $8.5 \%$ larger in the female $(P<0.05)$; b) the excretory ducts exhibited surface density, total external surface, surface-to-volume ratio, and absolute cell number, $18 \%, 33 \%, 14 \%$, and $44 \%$, respectively, larger in the females $(P<0.05)$; and $c)$ the pancreatic islets of the females exhibited volume density, total volume and absolute cell number, $20 \%, 27 \%$ and $27 \%$, respectively, larger than those of the males $(P<0.05)$.
\end{abstract}

The mammalian pancreas is a mixed gland with an exocrine function: secreting the pancreatic succus into the duodenum, and also an endocrine function: releasing the insulin and glucagon hormones into the blood stream.

The exocrine portion of the pancreas, more commonly designated the exocrine pancreas, is basically comprised of: serous acini containing centroacinar cells, intercalated ducts, excretory ducts and the principal excretory duct.

Since the pancreatic acini, comprising of typical secretory cells of enzymatic proteins, occupy a large portion of the pancreatic volume, this organ has been selected by many researchers as the ideal model system for studying the cellular and molecular biology of the secretory protein synthesis. Thus, the studies realized in the rodent pancreas, notably in the pancreatic acinar cells of guinea pigs, have enabled the various researchers to unveil the basic mechanisms that occur during the synthesis, intracellular transport, condensation, accumulation and exocytosis of secretory protein (Palade, 1975).
On the other hand, the exocrine pancreas of rodents has also served for the study of the basic events which occur during the ontogenetic development of a specific protein-secreting organ, such as for example, the epithelio-mesenchymal interaction, the cytodifferentiation, the role of the microfilaments in morphogenesis, the cellular proliferation, etc. (Rutter et al., 1964 and 1968 a, b, c). The majority of these studies into development were realized in the rat pancreas. In this sense, we highlight that the morphogenetic and cytodifferential events which lead to the development of the exocrine pancreas of the rat occur during its prenatal life (Pictet et al., 1972; Hisaoka et al., 1993; Taga, 1994).

On birth, the exocrine pancreas of the rat possesses all its epithelial structures already formed, but still immature. During the 1st month of postnatal life the pancreatic mass grows exponentially (Sesso et al., 1965). In the period from 2 to $30-40$ days there is a marked increase in the number and size of the acini and a diminishing of the periacinar

* CNPq Research Fellow (Proc. 521603/96-0),

** Recipient of FAPESP fellowship (Proc. 96/2126-0).

Correspondence to: Dr. Rumio Taga, Faculdade de Odontologia de Bauru - USP, Alameda Octávio Pinheiro Brisolla, 9-75. CP 73CEP: 17043-101, Bauru, SP, Brasil. 
spaces (Sesso et al., 1973). The morphometric analysis of the evolution of the absolute number of each cell category during the postnatal development of the rat pancreas, showed that in the period of 2 to 20 days post-partum, the number of acinar, centroacinar and duct cells grew exponentially with duplication times of $4.65,4.85$ and 4.89 days, respectively (Kachar et al., 1979).

With regard to the pancreas of adult hamsters, there is as yet no morphometric study published in the literature which serves as a comparison parameter for future experimental research of regarding its development.

Thus in the present research, the morphometric parameters of the various structures of the adult male and female Syrian golden hamster pancreas were evaluated at light microscope level using stereological methods.

\section{Materials and Methods}

The total of 36 adult golden hamsters (Mesocricetus auratus), aged 96 days, were used. These animals were obtained from colony maintained in the Central Animal House of the Dental School of Bauru, University of São Paulo, Brazil.

The animals were divided into 3 groups of 12 (6 males and 6 females), to be used, respectively, for the morphometric evaluations, determination of the gland density and evaluation of the shrinkage caused by the histological processing. The animals were reared from birth in lots of 8 offspring per mother, and weaned on day 21 .

\section{General histological procedure}

The animals were anaesthetized by inhalation of ethyl ether, always in the period from 10:00 to 12:00 a.m.. Immediately afterwards, the body mass was weighted using a Mettler P1000 scale. The pancreas was then carefully dissected, removed and weighed on a Mettler $\mathrm{H}-20$ precision scale, and fixed in $10 \%$ formalin solution in a phosphate buffer for one week, at room temperature. The material was rinsed overnight in running water and processed histologically with dehydration in ethanol, clearing in xylene and embedding in Paraplast (paraffin + plastic resin).

Semiserial $6 \mu \mathrm{m}$ thick sections were cut from the pancreas of the first group of 12 animals using a Leitz-Jung microtome, with a $60 \mu \mathrm{m}$ interval between sections, and stained by the Masson trichrome method.

Evaluation of processed gland volume

When determining absolute morphometric pa- rameters, such as for example, the absolute cell number, or the total volume of a morphological compartment in an organ, etc., it is necessary to know the volume of the organ after completing all the phases of the histological processing.

The fresh organ volume can be calculated from its fresh mass, provided that the organ's density is known. In the case of the hamster pancreas the density had not yet been established and it was necessary to evaluate its.

The processed volume of the gland $(\mathrm{Vp})$, or that is the glandular volume following all the histological procedures was calculated from the fresh gland mass (m), after the evaluation of its density (dgl) and the shrinkage factor caused by histological processing (Sf), using the formula: $\mathrm{Vp}=\frac{\mathrm{m} \times \mathrm{Sf}}{\mathrm{dgl}}$.

The density of the pancreas (dgl) was obtained from the animals of group 2 using the method of Scherle, following the recommendations of Pardini and Taga (1986).

The density of the adult hamster pancreas was measured in the 2 nd lot of 12 animals ( 6 males and 6 females), by the method of Scherle (1970). This gave a density of $\mathrm{dgl}=1.11 \mathrm{~g} / \mathrm{cm}^{3}$, with a variation coefficient of $4.1 \%$ (i.e. the standard deviation of the measurements expressed as a percentage of the mean).

The volume of the fresh organ suffers a discernible reduction in volume as it undergoes the various stages of the histological processing. In order to calculate its final volume, it is necessary to first determine the percentage of shrinkage suffered by the organ. In the present research, the average percentage of shrinkage caused by the histological procedures was evaluated in the 3rd lot of 12 adult hamsters by the method of Taga and Sesso (1978), giving $57.6 \%$, from which the shrinkage factor was calculated to be 0.424145 , with a variation coefficient in the measurements of $23.4 \%$.

Thus, the findings for the fresh pancreatic mass of $389.9 \mathrm{mg}$ for the male animals and $409.7 \mathrm{mg}$ for the females, gave a processed volume of $153.7 \mathrm{~mm}^{3}$ and $161.5 \mathrm{~mm}^{3}$, respectively.

Stereologic evaluation of volume density (Vvi), total volume (Vti), surface density (Svi), total external surface (Sti), surface-to-volume ratio (s/vi) and absolute cell numbers (Ni) of each glandular structure (i) and of nucleus volume density of the acinar cells ( $\rho n a c)$

These histological parameters were evaluated with a $100 \mathrm{X}$ oil-immersion objective and an $8 \mathrm{X}$ Zeiss Kpl eyepiece containing a Zeiss II integration grid comprising of 10 parallel lines and 100 points 
in a quadrangular area. The image of the grid was superimposed successively over the 50 histological fields which had been selected by systematic-stratified sampling (Weibel, 1969), and the following data were recorded: a) number of points $(\mathrm{Pi})$ which coincided with each of the pancreatic structures (i) and with the entire pancreas (P); b) number of points which coincided with the nuclei (Pnac) and the cytoplasm (Pcytac) of the acinar cells; c) number of nucleus images $(n)$ of each glandular structure (i); d) number of intersections (c) of the grid lines with the contours of the nucleus of each structure e) number of intersections (li) of the grid lines with the contour profile of the structures under study.

With these data and given the total length (L) of the grid lines, the total area examined (A), the distance between the grid lines (d), the thickness of the section $(t)$ and the processed pancreatic volume $(\mathrm{Vp})$, the following morphometric dimensions were calculated (Aherne \& Dunnill, 1982; Weibel, 1969): a) compartmental volume density (Vvi), Vvi $=\mathrm{Pi}$ / $\mathrm{P}$; b) total compartmental volume $(\mathrm{Vti}), \mathrm{Vti}=\mathrm{Vvi}$. $\mathrm{Vp}$; c) surface density $(\mathrm{Svi}), \mathrm{Svi}=2 \mathrm{li} / \mathrm{L}$; d) total external surface $(\mathrm{Sti}), \mathrm{Sti}=\mathrm{Svi} . \mathrm{Vp}$; e) surface-tovolume ratio (si/vi), si/vi $=\mathrm{Svi} / \mathrm{Vvi}$; f) absolute cell numbers $(\mathrm{Ni}), \mathrm{Ni}=2 \mathrm{n} . \mathrm{Vp} / \mathrm{A}(c / n . \mathrm{d}+2 \mathrm{t})$; and $\mathrm{g})$ nucleus volume density of the acinar cells ( $\rho$ nac), pnac $=$ Pnac $/$ Pnac + Pcytac.

The coefficient of variation (or error $=e$ ) present in the evaluation of volume density (Vvi), was determined using the formula of Schaefer (1970): $\mathrm{e}=\sqrt{1-V v i / P . V v i}$.

Evaluation of nuclear (Vnac) and cytoplasmatic (Vcytac) volume of the acinar cells

The orthogonal diameters $\left(D_{1}\right.$ and $\left.D_{2}\right)$ of 50 acinar cell nuclei per animal, were measured using a $10 \mathrm{X}$ Olympus ocular micrometer (Ramsden type), and a $100 \mathrm{X}$ oil-immersion objective. After calculating the arithmetic mean of the nuclei diameters $(D=(D 1+D 2) / 2)$ the mean radius $(\bar{R})$ was calculated for each animal. From this value the nucleus volume for each animal of the sample was determined using the equation $\mathrm{V}=4 / 3 \pi \bar{R}^{3}$ for structures with spherical nuclei.

The volume density of the nuclei of the acinar cells ( $\rho$ nac), as presented in item g) were overestimated due to the Holmes effect (WEIBEL, 1969). This overestimation was corrected using the correction factor (ko): ko $=(1-3 t) / 2$ (Weibel, 1969), where: $t=$ section thickness and $D=$ mean nucleus diameter. Thus, the corrected volume density of the nucleus ( $\rho$ nac.corr.) and corrected cytoplasm density ( $\rho$ cytac.corr.) will be: $\rho N a c . c o r r . ~=$

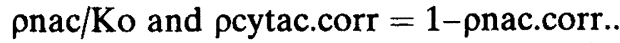

The cytoplasm volume (Vcytac) was calculated using the equation: Vcytac $=$ Vnac. pcytac.corr./ pnac.corr..

\section{Statistical analysis}

The results obtained from the male and female hamster were compared using analysis of variance (ANOVA), with the level of significance set at $P \leq 0.05$.

\section{Results}

Table 1 shows the morphometric results, comparison and statistical analysis for the morphological pancreatic compartments of the acini, centroacinar cells, intercalated ducts, excretory ducts, islets and stroma of the adult male and female hamsters.

Analysis of the data in Table 1 indicates that: - none of the pondered parameters of comparison indicated statistically significant differences between the sexes $(P>0.05)$;

- in the morphological compartments of the acini, the nucleus volume of the female was greater than in the male $(P<0.05)$, the remaining dimensions quantified showed no statistically significant difference $(P>0.05)$;

- none of the morphometric parameters evaluated in the morphological compartment of the centroacinar cells, intercalated ducts and stroma showed any statistically significant differences between the sexes $(P>0.05)$.

- the excretory ducts of the female hamsters exhibited a surface density, total external surface, surface-to-volume ratio and absolute cell number, respectively, of $18 \%(\mathrm{P}<0.05), 33 \%(\mathrm{P}<0.05)$, $14 \%(P<0.05)$ and $44 \%(P<0.05)$ greater than that of the males;

- regarding the endocrine pancreas, the females exhibited a volume density, total volume, and absolute cell number, respectively, $20 \%(P<0.05)$, $27 \%(\mathrm{P}<0.05)$ and $27 \%(\mathrm{P}<0.05)$ greater than in the males.

\section{Discussion}

The pancreas of rodents, notably the guinea pig (Cavia porcellus) and the laboratory rat (Rattus norvegicus) have served as an ideal model system for the study of cellular and molecular biology of secretory protein synthesis and development (Palade, 1975; Rutter et al., 1968 a, b, c). In relation to the hamster pancreas, little research has been published. Of the existing works, the majority refer to 
Table 1. Morphometric dimensions of the male and female hamster pancreas

\begin{tabular}{|c|c|c|c|}
\hline $\begin{array}{l}\text { Morphometric } \\
\text { Dimension }\end{array}$ & Male & Female & $\begin{array}{c}\text { Probability } \\
\text { Level }\end{array}$ \\
\hline Body mass (g) & $133.77 \pm 2.449^{\circ}$ & $140.56 \pm 7.982$ & $P>0.05$ \\
\hline Gland mass (mg) & $389.96 \pm 14.868$ & $409.68 \pm 21.420$ & $P>0.05$ \\
\hline Processed pancreatic volume $\left(\mathrm{mm}^{3}\right)$ & $153.67 \pm 5.862$ & $161.46 \pm 8.451$ & $P>0.05$ \\
\hline \multicolumn{4}{|l|}{ ACINUS (AC) } \\
\hline Volume density (\%) & $84.94 \pm 0.248$ & $84.11 \pm 0.377$ & $P>0.05$ \\
\hline Surface density $\left(\mathrm{cm}^{2} / \mathrm{cm}^{3}\right)$ & $900.22 \pm 22.730$ & $872.61 \pm 18.293$ & $P>0.05$ \\
\hline Surface-to-volume ratio $\left(\mathrm{cm}^{2} / \mathrm{cm}^{3}\right)$ & $985.94 \pm 45.982$ & $1,006.21 \pm 33.233$ & $P>0.05$ \\
\hline Total volume $\left(\mathrm{mm}^{3}\right)$ & $130.47 \pm 4.649$ & $130.95 \pm 7.651$ & $P>0.05$ \\
\hline Total surface $\left(\mathrm{cm}^{2}\right)$ & $137.54 \pm 6.228$ & $140.90 \pm 6.082$ & $P>0.05$ \\
\hline Nucleus volume $\left(\mu \mathrm{m}^{3}\right)$ & $60.07 \pm 0.937$ & $65.20 \pm 1.497$ & $P<0.05^{*}$ \\
\hline Cytoplasm volume $\left(\mu \mathrm{m}^{3}\right)$ & $1,581.73 \pm 41.989$ & $1,448.18 \pm 42.797$ & $P>0.05$ \\
\hline Cell number $\left(\times 10^{5}\right)$ & $394.94 \pm 15.072$ & $421.72 \pm 13.839$ & $P>0.05$ \\
\hline \multicolumn{4}{|l|}{ CENTROACINAR CELLS (CA) } \\
\hline Volume density (\%) & $1.13 \pm 0.046$ & $1.10 \pm 0.0412$ & $P>0.05$ \\
\hline Total volume $\left(\mathrm{mm}^{3}\right)$ & $1.70 \pm 0.076$ & $1.79 \pm 0.155$ & $P>0.05$ \\
\hline Cell number $\left(\times 10^{5}\right)$ & $29.41 \pm 3.065$ & $29.42 \pm 1.920$ & $P>0.05$ \\
\hline \multicolumn{4}{|l|}{ INTERCALATED DUCT (ID) } \\
\hline Volume density (\%) & $1.18 \pm 0.078$ & $1.10 \pm 0.043$ & $P>0.05$ \\
\hline Surface density $\left(\mathrm{cm}^{2} / \mathrm{cm}^{3}\right)$ & $23.07 \pm 0.512$ & $21.44 \pm 1.281$ & $P>0.05$ \\
\hline Surface-to-volume ratio $\left(\mathrm{cm}^{2} / \mathrm{cm}^{3}\right)$ & $2,038.12 \pm 118.83$ & $2,032.97 \pm 161.016$ & $P>0.05$ \\
\hline Total volume $\left(\mathrm{mm}^{3}\right)$ & $1.81 \pm 0.132$ & $1.71 \pm 0.018$ & $P>0.05$ \\
\hline Total surface $\left(\mathrm{cm}^{2}\right)$ & $3.55 \pm 0.150$ & $3.45 \pm 0.263$ & $P>0.05$ \\
\hline Cell number $\left(\times 10^{5}\right)$ & $17.77 \pm 1.796$ & $23.69 \pm 3.134$ & $P>0.05$ \\
\hline \multicolumn{4}{|l|}{ EXCRETORY DUCT (ExD) } \\
\hline Volume density (\%) & $1.57 \pm 0.085$ & $2.29 \pm 0.455$ & $P>0.05$ \\
\hline Surface density $\left(\mathrm{cm}^{2} / \mathrm{cm}^{3}\right)$ & $14.61 \pm 0.506$ & $17.28 \pm 1.097$ & $\mathrm{P}<0.05^{*}$ \\
\hline Surface-to-volume ratio $\left(\mathrm{cm}^{2} / \mathrm{cm}^{3}\right)$ & $866.62 \pm 96.878$ & $984.38 \pm 137.73$ & $\mathrm{P}<0.05^{*}$ \\
\hline Total volume $\left(\mathrm{mm}^{3}\right)$ & $2.40 \pm 0.091$ & $3.11 \pm 0.490$ & $P>0.05$ \\
\hline Total surface $\left(\mathrm{cm}^{2}\right)$ & $2.07 \pm 0.193$ & $2.76 \pm 0.157$ & $P<0.05^{*}$ \\
\hline Cell number $\left(\times 10^{5}\right)$ & $15.20 \pm 0.575$ & $21.91 \pm 2.537$ & $\mathrm{P}<0.05^{*}$ \\
\hline \multicolumn{4}{|l|}{ ISLETS OF LANGERHANS (IL) } \\
\hline Volume density (\%) & $3.80 \pm 0.211$ & $4.56 \pm 0.222$ & $\mathrm{P}<0.05^{*}$ \\
\hline Total volume $\left(\mathrm{mm}^{3}\right)$ & $5.84 \pm 0.407$ & $7.40 \pm 0.596$ & $\mathrm{P}<0.05^{*}$ \\
\hline Cell number $\left(\times 10^{5}\right)$ & $24.11 \pm 1.07$ & $30.57 \pm 2.088$ & $P<0.05^{*}$ \\
\hline \multicolumn{4}{|l|}{ STROMA (S) } \\
\hline Volume density (\%) & $7.72 \pm 0.276$ & $7.22 \pm 0.386$ & $P>0.05$ \\
\hline Total volume $\left(\mathrm{mm}^{3}\right)$ & $10.61 \pm 0.445$ & $11.79 \pm 0.456$ & $P>0.05$ \\
\hline
\end{tabular}

${ }^{\circ}$ Mean \pm standard error of the mean.

* Statistically significant diference.

studies of carcinogenesis induced by chemical substances such as nitrosamines (Pour et al., 1974). In this sense, we highlight that due to genetic factors the golden hamster presents great susceptibility to the development of induced malignant neoplasia. In the case of the pancreas, the chemically induced carcinoma presents a great similarity to the equivalent human pancreatic tumor (Pour, 1985).

The present study was realized with a view to establishing the morphometric dimensions of pancreas of normal adult Syrian golden hamsters, of both sexes, in order to serve as a normal parameter for studies involving experimental oncogenesis. Furthermore, the work aims to set a parameter of comparison for research which is presently being carried out in our laboratory into the normal pancreatic development of this rodent.

The morphological analysis of the Syrian golden hamster pancreas has shown a structural similarity to that of other rodents, though with minor characteristic differences between each species. Such that, the exocrine portion, comprised of serous acini, 
with centroacinar cells, intercalated ducts, excretory ducts and the principal duct have a very similar arrangement to the rat and mouse pancreas, in that its acini are not so large and compactly arranged as in the guinea pig. But the most remarkable finding in the golden hamster pancreas was its endocrine portion, with enormous islets of Langerhans exhibiting a typical cordonal arrangement.

The body mass of the animals used in the present research showed no difference between the sexes, as observed by Mendes-Filho (1974).

In the mouse there is also no difference in the body mass between the males and females (Pardini \& Taga, 1996). However, regarding rats, Sesso et al. (1965) detected that in rats aged 108 days, the males have a $34 \%$ greater body mass.

In relation to fresh pancreatic mass and to the corresponding processed volume, there was a small difference about $5 \%$ between the sexes, though this was not statistically significant. In rats, Sesso et al. (1965) observed a glandular mass of $673 \mathrm{mg}$ in males and $609 \mathrm{mg}$ in females.

The stereological analysis realized in the present work showed that the acini, centroacinar cells, intercalated ducts and stroma did not present any statistically significant difference in any of the dimensions evaluated, except for the nucleus volume of the acinar cells which were $8.5 \%$ greater in the females. These no statistically significant differences in the results suggests that these constituents of the exocrine parenchyma and the pancreatic stroma of hamsters, do not exhibit differences between the sexes in the geometric form, size, cellular volume, cell number and the relative volume occupied in the organ.

The only morphological compartment to present differences between the sexes was that of the excretory ducts in relation to their surface density, total surface, surface-to-volume ratio and absolute cell number. The values of these dimensions were all greater in the females. On the other hand, no statistically significant differences were observed in either the volume density or the total volume. The difference observed in the surface-to-volume ratio indicates that the diameter of the excretory duct is smaller in the females and the differences observed in the other morphometric parameters suggest that . these ducts are also longer and/or have more ramifications in the females.

The islets of Langerhans exhibit statistically significant differences in the three morphometric dimensions quantified in the compartment, i.e. the volume density, the total volume and the absolute cell number. These were all greater in the females. Thus the results indicate that the hamster endocrine pancreas is more developed in the females.
However, further morphometric research is necessary for to verify whether this difference is due to a greater number and/or size of the pancreatic islets in females.

In summary, the mean morphometric dimensions between male and female hamster were: acini: volume density $=84.52 \%$, total volume $=130.71 \mathrm{~mm}^{3}$, cellular volume $=1,577.59 \mu^{3}$ and absolute cell number $=408.33 \times 10^{5}$; centroacinar cells: volume density $=1.11 \%$, total volume $=1.75 \mathrm{~mm}^{3}$ and $a b$ solute cell number $=29.41 \times 10^{5}$; intercalated duct: volume density $=1.14 \%$, total volume $=1.76 \mathrm{~mm}^{3}$ and absolute cell number $=20.73 \times 10^{5}$; excretory duct: volume density $=1.93 \%$; total volume $=$ $2.75 \mathrm{~mm}^{3}$ and absolute cell number $=18.56 \times 10^{5}$; and stroma: volume density $=7.47 \%$ and total volume $=11.20 \mathrm{~mm}^{3}$.

\section{References}

1) Aherne W and Dunnill MS. Morphometry. London, Ed. Edward Arnold, 1982.

2) Hisaoka $M$, Haratake J and Hashimoto H. Pancreatic morphogenesis and extracellular matrix organization during rat development. Differentiation 1993; 53:163-72.

3) Kachar B, Taga R, Kniebel GA and Sesso A. Morphometric evaluation of the number of exocrine pancreatic cells during early postnatal growth in the rat. Acta Anat 1979; 103:11-15.

4) Mendes Filho A. Glândulas salivares maiores do hamster (Mesocricetus auratus). estudo estrutural, histoquímico, radioautográfico e bioquímico. Department of Histology and Embriology, Biomedical Institute. University of São Paulo (Doctoral Thesis). São Paulo, 1974.

5) Palade GE. Intracellular aspects of the process of protein synthesis. Science 1975; 189:347-58.

6) Pardini LC and Taga R. Evaluation of the density of the mouse submandibular gland by the method of Scherle. Rev Fac Odont Ribeirão Preto 1986; 23:205-7.

7) Pictet RL, Clark WR, Williams RH and Rutter RJ. An ultrastructural analysis of the developing embryonic pancreas. Devel Biol 1972; 29:436-67.

8) Pour P. Induction of unusual pancreatic neoplasma with morphologic similarity to humans tumors and evidence for their ductal ductular origin. Cancer 1985; 55:2411-16.

9) Pour P, Krüger FW, Chem D, Althoff J, Cardesa A and Mohr U. Cancer of the pancreas induced in the Syrian golden hamster. Am J Pathol 1974; 76:349-58.

10) Rutter WJ, Wessels NK and Grobstein C. Control of synthesis in the developing pancreas. Nat Cancer Inst Monogr 1964; 13:51-65.

11) Rutter WJ, Ball WD, Bradshaw WS, Clark WR and Sanders TG. Levels of regulation in cytodifferentiation. In: Hagen E, Wechsler W, Zilliken F. Ed. Experimental Biology and Medicine, Basel 1968a; 1:110-24.

12) Rutter WJ, Clark WR, Kemp JD, Bradshaw WS, Sanders TG and Ball WD. Multiphasic regulation in cytodifferentiation. In: Baltimore, Willians \& Wilkins. Epithelial mesenchymal interactions $1968 \mathrm{~b}, 114-131$.

13) Rutter WJ, Kemp JD, Bradshaw WS, Clark WR, Ronzio RA and Sanders TG. Regulation of specific protein synthesis in cytodifferentiation. J Cell Physiol 1968c; 72:1-18 
suppl. 1.

14) Schaefer A. The mathematical basis of stereology. "Microscopion(18 + 19)" Wild Heeburg Switzerland 1970; 7:3-13.

15) Scherle W. A simple method for volumetry of organs in quantitative stereology. Mikroskopie Bd 1970; 26:57-60.

16) Sesso A, Carneiro J, Cruz AR and Arruda Leite JB. La croissance du pancréas chez le rat pendant la vie post-natale. Acta Anat (Basel) 1965; 62:283-95.

17) Sesso A, Abrahamsohn PA and Tsanaclis A. Acinar Cell proliferation in the pancreas during early postnatal growth. Acta Physiol Lat Amer 1973; 23:37-50.

18) Taga R. Estudo morfológico, morfométrico, topoquímico, subcelular e em réplicas de criofatura da célula acinosa pancreática do rato durante a vida fetal. Bauru. Faculty of Odontology of Bauru - University of São Paulo (Livre Docência Thesis), 1994.

19) Taga $R$ and Sesso $A$. Avaliação do número de células de órgãos pela dosagens bioquímica de dna em homogeneizados e por contagem direta através de métodos morfométricos. Ciênc Cult 1978; 30:1232-6.

20) Weibel ER. Stereological principles of morphometry in electron microscopic cytology. Int Rev Cytol 1969; 26:235302. 